\title{
NOTAS PARA UM DIÁLOGO ENTRE CULTURAS \\ - AS TRADUÇŌES DE FAGUNDES VARELA DE POEMAS SÂNSCRITOS
}

\begin{abstract}
Mário Ferreira*
RESUMO: O presente trabalho tem por objetivo analisar, à luz de duas orientaçōes tradutológicas (a ontológica e a cognitiva), as traduçōes de textos do Rgveda publicadas em 1869 por Fagundes Varela, em Cantos ermo e da cidade. Postula ele que as traduçōes de Fagundes Varela, nāo obstante a sua imperfeição enquanto resgate idiomático-o que as inabilita como reconstituiçāo da identidade lingüistica do original-, constituem operaçōes semiológicas não desprovidas de interesse, dadas as relaçōes intertextuais que suscitam e dado o estimulo que, como objeto cognitivo, provocam, no que respeita ao estudo dos métodos e dos procedimentos da tradução do texto artístico.
\end{abstract}

Palavras-chave: tradutibilidade, Fagundes Varela, Rgveda, poesia sânscrita.

No estudo das relações entre a palavra e o homem, um espaço há que se conferir obrigatoriamente à problemática da tradução, porquanto é o ato de traduzir inerente à inserção no mundo do ser humano, dada a necessidade que tem este seja de construir em termos simbólicos os estimulos oriundos da esfera do real (o que constitui, empregando a terminologia de Heidegger, uma transposição da coisa-em-si para o ser), seja de apropriar-se do sentido do ser gerado no cruzamento dos sistemas múltiplos de significação. Como toda e qualquer palavra é um símbolo - quer dizer, um instrumento de mediação -, o ato de manipulá-la implica por princípio

(*) Professor do Departamento de Letras Clássicas e Vernảculas. FFLCH/USP. 

Fagundes Varela de poemas sânscritos. Lingua e Literatura, $\mathrm{n}^{\circ} 23$. p.151-169, 1997.

uma operaçāo tradutora, relativa ao mecanismo de configuraçāo do sentido do signo na rede de relaçōes em que ele se insere. Entendida deste modo, a tradução configura-se como atividade cujo âmbito dilata os limites do mero confronto entre dois sistemas de significado, localizando-se ela no âmago da constituição mesma do ser humano. Para recorrer a uma fórmula reduzida: a semiose, o processo de construir o sentido, torna humano o homem; a semiose é tradução.

O presente texto insere-se no âmbito das premissas esboçadas sumariamente no que antecede, circunscrevendo-se ele, contudo, por razōes de espaço, a um dos temas afetos à tradutologia, relativo à tradutibilidade do texto artístico, a qual é aqui abordada no âmbito da construção intercultural do sentido - no âmbito, pode-se dizer, de um diálogo entre culturas.

Constituem o corpus deste escrito as traduçōes de textos sânscritos publicadas, em 1869, por Fagundes Varela, na obra Cantos do ermo e da cidade.

Os estudos tradutológicos têm defendido, nos anos recentes, em uma de suas orientações ${ }^{1}$, o postulado de que a tradução de textos artisticos constitui um ato lingüístico dotado de plena exeqũibilidade operatória, desde que se atribua à operação tradutora o desiderato, não de reconstruir, no texto de chegada, a totalidade ontológica do texto de partida, mas sim o de configurar, no texto de chegada, uma hipótese de cognição do sentido do texto de partida. Parece clara a razão de estabelecer tais distinções. O primeiro desiderato, regido pelo imperativo da perfeição, o qual projeta a sua sombra, a imperfeição, transforma a operaçāo tradutora em ato fadado obrigatoriamente ao fracasso: sua meta - configurar no texto de chegada a identidade do texto de partida - radica numa impossibilidade lógica, porquanto implica construir o duplo do ser - ou, para empregar os termos da lingüistica, formular um sentido único me-

(1) Cf. Ferreira (1991: passim). 
diante o concurso, em si contraditório, de sistemas diversos de significação. $\mathrm{O}$ segundo desiderato, que confere à tradução o estatuto de ato cognitivo, recusa, ao contrário, a polaridade perfeição/imperfeição, entendendo que a operação de tradução constitui um processo heuristico virtualmente aberto, eis que todo objeto de conhecimento - e um texto artístico efetivamente o é - admite um universo de leituras que se pode desdobrar ao infinito. A esse respeito - em relação ao caráter virtualmente aberto da obra de arte, idéia que ê aliás sustentada por inúmeros trabalhos na área da teoria literária, e também recentemente na lingūística ${ }^{2}$-, pode-se lembrar a afirmação de Chesterton, segundo a qual hoje se pode ler e compreender a obra de Shakespeare de forma superior à da leitura que dela tinha o próprio autor, visto que temos nós hoje não só o texto shakespeariano como também toda a reflexão que a ele se acrescentou e que se tornou, devido ao processo de formalização das tradiçōes literárias no Ocidente, parte integrante do modo pelo qual essa obra é hoje decodificada e compreendida.

Entendidos nestes termos os objetivos da tradução artística, os métodos de operação que lhe são próprios adquirem também perfis contrastantes. Na tradução de cunho ontológico, como assim propomos chamá-la - que visa ao ato perfeito de transposição de sentido, ou seja, emular o mesmo pelo outro -, a operação tradutora é aferida em termos da perfectibilidade da relação dos sistemas em confronto - assim, o contraste entre dois idiomas, entre dois sistemas, ou entre dois meios -, o que pressupõe a existência de uma identidade reconhecida no texto de partida e a necessidade de recuperar tal identidade. Na tradução de cunho cognitivo, que visa ao assédio da matriz de sentido do texto de partida, a operação de tradução é sempre entendida como provisória, na medida em que considera que o sentido dos textos em confronto é sempre passivel de uma reconfiguração intelectiva. Na tradução ontológica, o problema da tradutibilidade circunscreve-se à propriedade dos sistemas de sentido em contraste. Na tradução cognitiva, a conversão de sentidos em sistemas de significação convoca a totalidade dos sentidos

(2) Cf. Ferreira (1991: 88-159). 
FERREIRA, Mário. Notas para um diálogo entre culturas - as traduçōes de Fagundes Varela de poemas sânscritos. Lingua e Literatura, $n^{\circ} 23$, p.151-169, 1997.

constelados. Em suma, a tradução ontológica limita-se ao lingũistico. A tradução cognitiva abrange o lingũístico e abre-se ao extralingūistico; sua dimensāo é semiológica, entendendo-se este termo na acepção que Saussure, no Curso de lingüistica geral (s.d.: 44), lhe dá, ou seja, como um conjunto de sinais em circulação "no seio da vida social"

No que segue, procura-se analisar, na perspectiva das teorias de tradução referidas, as traduçōes de textos do Rgveda publicadas em 1869 por Fagundes Varela, na obra Cantos do ermo e da cidade.

Não cabe aqui procurar traçar o perfil da obra desse autor, que é decerto já bastante conhecida. Parece importante mencionar, apenas, que a obra em pauta - que é cronologicamente a penúltima editada em vida de Fagundes Varela - foi publicada quando o autor contava 27 anos de idade, portanto seis anos antes de sua morte, apresentando ela as caracteristicas da fase mais madura se é que se pode empregar tal palavra tratando-se de autor falecido tāo precocemente -, caracterizada pelo despojamento estilistico, pela adoção de um ideário cético e agnóstico e pelo culto da natureza como um dado que deve ser apreciado em si mesmo e por si mesmo, sem o recurso a qualquer ideal de transcendência - numa atitude que, em parte, lembra o antiidealismo de Fernando Pessoa expresso no heterônimo Alberto Caieiro.

Os poemas sânscritos que constam dessa obra são três, a saber: "Oração fúnebre" "Ao Deus criador" e "Hino à Aurora” que são claramente identificados, nos cabeçalhos, como pertencentes ao Rgveda. Os três poemas fecham o volume e sāo antecedidos por um fragmento cômico, intitulado "Leviandades de Cinthia" aparentemente projetado para a encenaçāo teatral, tendo por mote as dores de coração de dois amantes traidos que, sem o saber, partilham a mesma mulher.

Eis os textos referidos, transcritos conforme a edição de Visconti Coaracy (s.d., vol II: 332-327): 
ORAÇÃO FUNEBRE

(Rig-Veda, VIII, 14)

Segue o caminho antigo onde passaram

Outr'ora nossos pais. Vai ver os deoses

Indra, Yama e Varuna.

Livre dos vicios, livre dos peccados,

Sobe á eterna morada, revestido

De fórmas luminosas.

Volte o olhar ao sol, o sopro aos ares, A palavra á amplidão, e os membros todos

Ás plantas se misturem.

Mas a essência immortal, aquece-a, oh! Agnis, 10

E leva-a docemente á clara estancia

Onde os justos habitão.

Para que ahi receba um novo corpo,

E banhada em teu halito celeste

Outra vida comece...

Desce á terra materna, tão fecunda,

Tão meiga para os bons que a fronte encostāo

Em seu humido seio.

Ella te acolherá terna e amorosa,

Como em seus braços uma māi querida

Acolhe o filho amado. 

Fagundes Varela de poemas sânscritos. Lingua e Literatura, $n^{\circ} 23$, p.151-169, 1997.

\section{AO DEOS CREADOR}

(Rig-Veda, VIII, 7)

O Deos da Luz appareceu, e apenas

Elle mostrou-se foi senhor do mundo,

$E$ encheu o céo e a terra...

Gloria ao Deos que ha partido o ovo de ouro!

- Que Deos receberá nosso holocausto?

D'elle dimana a Vida, a força, o animo:

Á lei que elle traçou todos os seres

Submissos se curvão...

Gloria ao Deos (...)

- Que Deos (...)

Foi elle que formou estas montanhas, $E$ este mar que rebrame sem descanso, Os sabios o disserão...

Gloria ao Deos (...)

É por elle que o céo, a terra, os astros,

Tremem de amor e tremem de desejos

Quando o sol apparece...

Gloria ao Deos (...)

Quando as tumidas ondas que conservāo

A essencia universal se revolverão,

Elle agitou-se n'ellas...

Gloria ao Deos (...)

Ah! Proteja-nos elle, o Deos piedoso,

O espirito das cousas invisiveis,

O Senhor do universo!

Gloria ao Deos (...) 
HYMNO A AURORA

(Rig-Veda, I, 8)

Ella mostrou-se emfim!

Ella mostrou-se emfim, a mais formosa,

A mais bella das luzes!

Por esse azul setim,

Caminhando tão linda e tão garbosa,

Aonde nos conduzes?

Aonde, branca Aurora?

Filha tambem do Sol, a Noite escura

Tua estrada marcou.

Com as lagrimas que chora

A vasta senda da eternal planura

Ao passar orvalhou.

Unidas pelo berço,

Ambas iguaes, eternas, successivas

Na marcha e na existencia...

Percorreis o universo, Aurora e Noite, sempre redivivas,

Oppostas na apparencia.

Rosea filha do Dia, Brilhante a nossos olhos appareces,

Cheia de gloria e amor;

E espalhas a harmonia, A vida, o gozo, ao mundo que esclareces Com teu sacro esplendor. 
FERREIRA. Mário. Notas para um diálogo entre culturas - as traduçōes de Fagundes Varela de poemas sānscritos. Lingua e Literatura, $n^{\circ} 23$. p.151-169, 1997.

Segues a mesma senda

Das auroras passadas, e precedes

As que estão no futuro.

Rasgas da Sombra a venda, $\mathrm{E}$ os negros planos previdente impedes

Do crime horrido, escuro.

Ha muito que passaram

Os que virão no céo luzir outr'ora

Teu fulgido clarão.

Seus olhos se apagaram, E nós por nossa vez tambem agora 35

Vemos-te n'amplidāo.

Na bibliografia referente ao autor, publicada em língua portuguesa, não se encontra nenhuma referência substancial a estes poemas, o que é de estranhar, visto que eles são exemplares únicos na obra de Varela, que, ao que parece, não tinha o hábito de traduzir textos alheios - a não ser, como os que fez na juventude, na forma de pastiches, mas aí com vistas a expor, com intençōes satíricas, os cacoetes e ridículos dos poetas clássicos, sendo Camōes a sua vitima predileta. Na obra mesma, Varela não faz referência também aos textos originais, a nāo ser, como se disse, a identificação parcial (e, em todas as vezes, errônea) da fonte -, embora não seja dificil compreender a razão de sua inserção no corpo da obra, dadas as correlaçōes que tais poemas apresentam com os temas básicos de sua melhor poesia. Também não é dificil rastrear as fontes a que Varela recorreu. Não há dúvida de que o autor compulsou a tradução integral do Rgueda, publicada em francês, em Paris, por Auguste Langlois, em quatro tomos, entre os anos 1848 e 1851, portanto, dezoito anos antes da publicação dos Cantos. Há duas outras traduçōes a que Varela poderia ter tido acesso - as de Th. Rosen (que é incompleta) e de $\mathrm{H}$. $\mathrm{H}$. Wilson, publicadas respectivamente 
em 1838 e 1850 . Mas as evidências apontam para a obra de Langlois como texto de fonte. ${ }^{3} \mathrm{E}$ isto por duas razōes. A primeira encontra-se na numeração dos poemas que Varela faz constar em seu livro. Essa numeração corresponde à divisão do texto em oito partes, chamada astaka, que é alternativa à divisão em dez partes, chamada mandala -, e que é utilizada por Langlois, que não registra senão essa forma de divisão do texto. É certo que a tradução de Wilson, adotando a divisão em oitavas, registra também a numeração em décadas. Deve-se contudo lembrar que o inglês não era a lingua de predileção de Varela, que, como se sabe, conhecia as obras do romantismo inglês por meio de suas traduçōes francesas. Uma outra evidência é textual. No poema "Ao Deus criador" no último verso do refrão, Varela emprega a palavra holocausto, que é tradução do termo sânscrito havih, "oblação" Entre os tradutores já citados apenas Langlois utiliza tal palavra (par. 1), que é, aliás, uma traduçāo bastante insatisfatória. Há outras evidências semelhantes, mas não cabe aqui referi-las.

Encontra-se, pois, na obra de Fagundes Varela, uma tentativa de tradução de três poemas sânscritos - mais especificamente, três poemas do sânscrito chamado védico, assim qualificado por causa da obra, Veda, de que tal lingua é veiculo -, vertidos a partir duma tradução francesa, que é hoje considerada bastante deficiente pelos sanscritistas. ${ }^{4}$ Como então aferir o valor das versōes de Varela?

Para responder a isto, cumpre retomar a referência às orientaçōes tradutológicas citadas anteriormente.

Avaliadas na perspectiva da traduçāo de cunho ontológico, as traduçōes de Varela são - em resumo - bastante imperfeitas, visto que apresentam inúmeros defeitos de controle lingüístico.

Em primeiro lugar - como já mencionado -, suas versões não recorrem ao texto original, o que, em principio, por si só, já implica um conflito com relação à totalidade e à identidade do original.

(3) Ver, no "Apêndice", para cotejo com as traduçōes portuguesas, as versões de Langlois.

(4) A propósito, Renou, em uma de suas obras (1945: s.v. Rigueda), tacha-a de "muito insuficiente", E, em outra (1928: 4), de "o mais deplorável empreendimento jamais tentado no dominio védico". 
FERREIRA, Mário. Notas para um diálogo entre culturas - as traduçōes de Fagundes Varela de poemas sânscritos. Lingua e Literatura, $\mathrm{n}^{\circ} \mathbf{2 3}$, p.151-169, 1997.

Por outro lado, não procuram elas também estabelecer, ainda que em referência ao texto de mediaçāo, uma relação de equivalência 1:1. São elas, a esse respeito, bastante livres. O poema "Ao Deus criador" conta seis estrofes, contra dez do texto francês; no poema "Hino à aurora" a relação é doze contra vinte; e, na "Oração fúnebre" sete contra catorze.

Em terceiro lugar, é bastante evidente que as versões de Varela procuram apagar, em sua transposiçāo para o nosso idioma, de modo radical, os elementos de contexto mais marcados dos textos de partida - e que a versão de Langlois conserva. A esse respeito, pode-se observar que as marcas de enunciaçāo dos textos de partida estão ausentes da versão portuguesa, apesar de constituirem elementos bastante evidentes - pode-se dizer, efetivamente estruturais - na poética védica, que enfeixa, sempre, um enunciador (necessariamente, um brâmane ritualista) e um enunciatário (uma divindade específica evocada pelo rito, a qual se quer manipular), conjugados ambos, enunciador e enunciatário, num contexto situacional, o rito cósmico-litúrgico, que a fala, ao se verbalizar, constitui. Nos textos de Varela, o enunciador circunscreve-se a um eu não especificado, o enunciatário torna-se vagamente subentendido e os dados de contexto se esbatem. Outros indícios desse apagamento encontram-se também na escolha vocabular das versões portuguesas, que reduzem ao minimo os vocábulos específicos do contexto védico, por simples omissão (especialmente no caso dos nomes de deuses, ritualistas, utensilios ou ritos), ou por traduções redutoras (assim, em "Oração fúnebre" [1. 2], pais por pitârâs, propriamente "ancestrais patrilineares iniciadores dos clãs e responsáveis pela fundação das instituições humanas” que no texto são evocados para justamente apontarem ao morto o seu destino. Há também, nos poemas, traduçōes deslocadas de contexto (assim, em "Ao Deus criador" [1. 5], holocausto, por havih, "oblação lançada ao fogo"; em "Oração fúnebre" [1. 4], vícios e pecados, dois substantivos para um único vocábulo, por papa, que significa propriamente "falta cometida em relaçāo a um preceito ritualístico"), ou traduçōes simplesmente acrescidas ao texto (como essência imortal ["Oraçāo fúnebre" 1. 10], tremem de amor, tremem de desejos ["Ao Deus criador, 1. 16], 
azul cetim [que é tributário do léxico romântico], rósea filha do dia [eco da Odisséia?] ["Hino à aurora" 1. 4 e 19, respectivamente]). Além de uma leitura reencarnacionista, na "Oração fúnebre" do destino da alma, a qual, no texto sânscrito, apenas se funde de volta na natureza, sem, como diz o poema (1. 13), "para que aí receba um novo corpo"

Por fim, as traduçōes de Varela não permitem entrever quaisquer caracteristicas da identidade do sistema idiomático inscrito nos textos - o que é uma virtude esperada das traduções interlinguais. Ao contrário, os textos das traduçōes são marcadamente vernaculares, estando concebidos num registro bastante apurado da língua portuguesa.

Tais são alguns dos defeitos que as traduções de Fagundes Varela apresentam. Apontá-los não significa, contudo, esgotar as possibilidades de aferição suscitadas pelo trabalho do poeta. Ao contrário, pode-se demonstrar que, recusada a perspectiva da tradução ontológica, que se funda no vetor da perfeição, e lidos na perspectiva da tradução cognitiva, os poemas de Varela apresentam não poucas virtudes heuristicas, em relaçāo à matriz de sentidos dos textos sânscritos.

A esse respeito, cabe observar, preliminarmente, que as traduções portuguesas procuram recuperar o cunho métrico das estrofes originais, que a tradução de Langlois descura e que é nuclear na enunciação da fala ritualística. É certo que a escolha dos metros realizada por Varela nada tem que ver com os metros originais, que exercem uma importante função construtiva no texto ritualístico, razão por que eram estabelecidos de forma complexa e meticulosa, segundo fundamentos que não importa aqui referir. A escolha de Varela é intuitiva, mas, não obstante isto, vai ao encontro de uma exigência de cognição do texto original, a que as traduções do Rgveda, em sua totalidade, não obedecem, apesar de feitas com conhecimento da lingua e com base diretamente nos textos originais.

Eis um segundo ponto. Como já se disse antes, as traduçōes de Varela apresentam grande liberdade quanto à transposição das estrofes do texto de mediação, recorrendo a cortes e mesmo à con- 
FERREIRA, Mário. Notas para um diálogo entre culturas - as traducōes de Fagundes Varela de poemas sânscritos. Lingua e Literatura, $\mathrm{n}^{\circ} \mathbf{2 3}$, p.151-169, 1997.

densação de vários textos. Isto é, com efeito, um atentado à inteireza do sentido de partida. Mas, analisando-se as traduçōes portuguesas, é possivel observar que elas são extremamente coesas, no que respeita às suas escolhas temáticas e às figuras a que recorrem. Parece evidente que as traduçōes de Varela efetivam uma seleçāo de elementos constantes no texto de partida - como se pretendessem elas pontuar apenas determinados torneios metafóricos -, aqueles, aliás, relativos aos temas da ciclicidade da vida e da morte, da celebração da natureza e da apreciação da ordem cósmica, que são estruturais nos textos védicos e recorrentes na obra de Fagundes Varela. Vistas nesta perspectiva, as traduçōes adquirem um contorno diverso, redefinindo-se elas como releituras intertextuais extremamente interessantes, o que redunda, por um lado, na inserçāo da obra do poeta no grande curso da literatura universal e, por outro, na revigoraçāo das metáforas dos textos védicos. Mencionemos, quanto a isto, apenas o verso, no "Hino à aurora" (1. 28), "Rasgas da sombra a venda" que traduz, de modo intuitivamente magistral, a frase sânscrita naktavastram usah hanti/ que figura em Langlois (par. 14) como um flácido “[A aurora] rechaça a deusa negra"

Ainda neste sentido, cabe observar também que, nos três poemas de Varela, estāo afirmados valores e práticas - como a transmigraçāo da alma, o culto panteista da natureza, o ceticismo gnóstico - muito distantes da cultura brasileira do século XIX, em relação à qual, aliás, também, a obra e a vida do poeta parecem deslocados. Em um de seus poemas, Varela disse de si mesmo - quase antecipando o gauche drummondiano - que "passava na vida errante e vago" (in "Soneto" Vozes da América). É lícito, talvez, entrever no gesto da produção das versões em pauta, a tentativa de Varela de tornar estranho, por contraste, o conhecido, forçando e fustigando, com base na antigüidade e, por conseqüência, autoridade do texto védico, o sistema de valores dos contemporâneos, perante os quais não admite (como está em "Eu amo a noite" de Cantos do ermo e da cidade) "a fronte curvar por terra" O tema do poeta em antagonismo com o meio não é alheio à obra de Varela. Os signos védicos, no intertexto vareliano, inserem-se nesta perspectiva. 
Outro aspecto que cumpre assinalar - porque é, de fato, um achado cognitivo das traduçōes de Varela - é que estas, não obstante apagarem a enunciação ritualística dos textos védicos, propõem uma recontextualização da fala original, inserindo-a no âmbito da temática do contraste entre o "ermo e a cidade" - contraste este que, embora não explicitado no Rgveda, não é de modo nenhum estranho à tradução textual sânscrita (conforme se pode observar na oposiçāo, ainda no periodo védico, entre os textos brâhmana e âranyaka, concebidos segundo proposições em grande parte antitéticas). Observe-se que, aqui, as traduçōes de Varela propōem uma reconsideração do locus situacional do texto védico, antecipando, há quase um século, proposiçōes que só em tempos recentes têm sido aventadas.

Uma última consideração, relativa às virtudes cognitivas das traduçōes de Varela, diz respeito à finalidade que o autor, ao agir como tradutor, parece atribuir à operação de tradução. Parece que sua mensagem é bem clara - e consiste em afirmar a liberdade que tem o tradutor de estabelecer um diálogo não submisso com uma tradição textual - liberdade que, em si mesma, não tem limites, e que configura, no curso e recurso das interaçōes intertextuais, um processo de incorporaçōes e projeçōes potencialmente criativo.

Colocados - de forma bastante sumária - estes pontos, esboçam-se algumas conclusōes:

A primeira, de que é salutar pensar o problema da tradução artistica sob perspectivas múltiplas, que podem até ser contraditórias entre si - como a oposição entre as orientaçōes ontológica e cognitiva -, mas que permitem, por meio da contradição mesma, manter os pontos de vista da questão em oportuno equilíbrio precário.

A segunda é de que o ato de traduzir não é uma operação apenas lingüística, mas implica o concurso de várias outras áreas humanas afins, especialmente a sociologia, a história e a teoria literária, constituindo, quando se trata do confronto entre textos de origens diversas, um verdadeiro diálogo de culturas, com o que se estimula um fértil programa de análise da circulação em contexto dos signos. Já se mencionou antes que a tradução cognitiva é um 
FERREIRA, Märio. Notas para um diálogo entre culturas - as traduç̄es de Fagundes Varela de poemas sânscritos. Lingua e Literatura, $\mathrm{n}^{\circ} 23$, p.151-169, 1997.

trabalho semiológico, no sentido que Saussure dá a este termo. Traduzir significa, nesta perspectiva, estudar os signos na intercorrência de todos os vetores possiveis de construçāo do sentido.

A terceira conclusão, essa relativa às traduçōes de Varela, propōe que tais textos, nāo obstante a sua imperfeição enquanto trabalho de resgate idiomático - o que as inabilita como reconstituiçāo da identidade lingūística do original -, constituem operaçōes semiológicas não desprovidas de interesse, dadas as relaçōes intertextuais que, como criação de sentido, elas suscitam, sendo um de seus não poucos méritos o de provocar respostas para a indagaçāo da verdade do ato de traduçāo.

A última conclusão é antes um estímulo - e diz respeito, nesta linha mesma sugerida pelos poemas de Varela, à oportunidade de aprofundar o estudo das projeçōes interculturais de sentido. A este respeito, os estudos clássicos oferecem vasto rol de possibilidades - como, por exemplo, fora da domínio indiano, para citar apenas um, o estudo da Antigona, nas versões de Euripedes, de Hölderlin e Carl Orff. É lícito pensar que tais estudos podem efetivamente alargar a compreensão dos processos de formação do sentido

\section{BIBLIOGRAFIA}

COARACY, Visconti (org.) (s.d.). Obras completas de L. N. Fagundes Varella. Rio de Janeiro, Livraria Garnier.

FERREIRA, M. (1991). A tradutibilidade do texto artístico. Elementos para a construçāo do algoritmo tradutológico. São Paulo, tese de doutoramento na F.F.L.C.H./USP, inédita.

LANGloIS, A. (1872). Rig-Véda. Paris, Maisonneuve et Cie.

Les maîtres de la philologie védique (1928). Paris, Paul Geuthner.

RENOU, L. (1945). Littérature sanskrite. Paris, Adrien Maisonneuve.

ROSEN, Th. (1850). Rig-Veda. Berlin, V. P. Verlag.

SAUSSURE, F. De (s.d.). Curso de lingũistica geral. Lisboa, Publicaçōes

Dom Quixote.

WILSON, H. H. (1850). Rg-Veda Samhitâ. Délhi, Nag Publishers, 6 vols., reed. 
ABSTRACT: This paper intends to analyze, the basis of two translational orientations (the ontological and the cognitive ones), Fagundes Varela's translations of Rgveda texts, published in 1869, in Cantos do ermo e da cidade. It postulates that those translations, in spite of their imperfectness as idiomatically adequate - which disqualifies them as reconstitution of the original text's linguistic identity -, constitute interesting semiological operations due to the intertextual relations that they imply and owing to the stimulus they provoke as cognitive object, concerning the study of the methods and also the proceedings of the translation artistic text.

Keywords: artistic text translation, Fagundes Varela, Rgveda, sanskrit poetry.

\section{APENDICE}

Tais são as traduções de Langlois, utilizadas provavelmente como fonte por Varela, reproduzidas segundo a ordem dos poemas constantes em Cantos do ermo e da cidade:

HYMNE VII, VI, 13 [ $=\mathrm{X}, 18$, na versão em décadas]

1. O Mrityou, suis une outre voie; la voie qui t'est propre n'est pas celle des dieux. Je parle (à un être) qui a des yeux et des oreilles. Épargne nos enfants, épargne nos hommes./ 2. Si vous parvenez à arrêter le pas de Mrityou et à prolonger votre vie, soyez purs et brillants; ayez de nombreux enfants, de grandes richesses. Distinguez-vous par vos sacrifices./ 3. La vie et la mort se succèdent. Que l'invocation que nous adressons aujourd'hui aux dieux nous soit propice! Livron-nous au rire et au bonheur de la danse, et prolongeons notre existence./ 4. Voici le rempart dont je protége les vivants. Qu'aucun autre, parmi ce peuple, ne s'engage dans cette route. Qu'ils vivent cent et cent automnes. Qu'ils enferment Mrityou dans sa caverne. / 5. Les jours et les saisons se succèdent heureusement; le plus jeune remplace le plus ancien. $O$ (Dieu) qui soutiens (les hommes), fais que la vie de ce peuple soit ainsi disposée./ 6.Levezvous; entourez celui que le temps a frappé, et, suivant votre âge, faites 
FERREIRA, Mário. Notas para um diálogo entre culturas - as traduçōes de Fagundes Varela de poemas sânscritos. Lingua e Literatura, $\mathrm{n}^{\circ} 23$, p.151-169, 1997.

des efforts pour le soutenir. Gue Twachtri, distingué par sa noble lignée, soit touché de votre piēté, et vous accorde une longue vie./ 7. Laissez approcher avec leur beurre onctueux ces femmes vertueuses qui possèdent encore leur époux. Exemptes de larmes et de maux, convertes de parures, qu'elles se lèvent devant le foyer./ 8. Et toi, femme, va dans le lieu où est encore la vie pour toi. Retrouve dans les enfants qu'il te laisse celui qui n'est plus. Tu as été la digne épouse du maître à qui tu avais donné ta main./ 9. Je prends cet arc dans la main du trépassé pour notre force, notre gloire, notre prospérité. $O$ toi, voilà ce que tu es devenu. Et nous, en ces lieux, puission-nous être des hommes de coeur, et triompher de tous nos superbes ennemis!/ 10. Va trouver la Terre, cette mère large et bonne, qui s'étend au loin. Toujours jeune, qu'elle soit douce comme un tapis pour celui qui a honoré (les dieux) par ses présents. Qu'elle te protége contre Nirriti./ 11. O Terre, soulève-toi. Ne blesse point (ses ossements). Sois pour lui prévenante et douce. O Terre, couvre-le, comme une mére (couvre) son enfant d'un pan de sa robe./ 12. Que la Terre se soulève pour toi. Que sa poussière t'enveloppe mollement. Que dans ces maisons chaque jour coule de ghrita; qu'elles te présentent un asile./ 13. J'amasse la terre autour de toi; je forme ce tertre, pour que (tes ossements) ne soient point blessés. Que les Pitris gardent cette tombe. Gu'Yama creuse ici ta demeure./ 14. Les jours sont pour moi ce que les flèches sont pour la plume qu'elles emportent. Je contiens ma voix, comme le frein (contient) le coursier.

HYMNE VIII, VII, $2[=\mathrm{X}, 121]$

1. Le (Dieu) au germe d'or apparait. Il vient de naître, et déjà il est le seul maitre du monde. Il remplit la terre et le ciel. A quel (autre) dieu offririons-nous l'holocauste?/ 2. Il donne la vie et la force. Tous les êtres, les Dieux (eux-mêmes), sont soumis à sa loi. L'immortalité et la mort ne sont que son ombre. A quel (...)/ 3. Il est par sa grandeur le seul roi de toute ce mond qui voit et qui respire. Il est le maitre de tous (les animaux), bipèdes et quadrupèdes. A quel (...)/ 4. Sa grandeur, ce sont ces (montagnes) couvertes de frimas, cet Océan avec ses flots, ces régions (célestes), ces deux bras (qu'il étend). A quel (...)/ 5. Par lui ont été solidement établis le ciel, la terre, l'espace, le firmament. C'est lui qui dans lair a répandu les ondes. A quel (...)/6. Le Ciel et la Terre affermis 
par ses soins ont frémi du désir de le voir, alors que le soleil brille à l'orient. A quel (...)/ 7. Quand les grandes Ondes sont venues, portant dans leurs sein le germe universel et enfantant Agni, alors s'est développée l'âme unique des Dieux. A quel (...)/ 8. Avec grandeur il voit autour de lui ces Ondes qui contiennet la Force et enfantent le Sacrifice. Parmi les Dieux il est le Dieu incomparable. A quel (...)/ 9. Gu'il nous protége, celui qui, accomplissant sa pieuse fonction, a engendré le Ciel et la Terre, celui qui est le père des grandes et belles Ondes. A quel (...)/ 10. $\mathrm{O}$ Pradjâpati, ce n'est point au autre que toi qui a donné naissance à tous ces êtres. Accorde-nous les biens pour lesquels nous t'offrons le sacrifice. Puissions-nous ètre les maîtres de la richesse!

HYMNE I, VIII, 1 [= I, 113]

1. La plus douce des lumières se lève; elle vient de ses rayons colorer partout la nature. Fille du Jour, la Nuit a préparé le sein de l'Aurore, qui doit être le berceau du Soleil./ 2. Belle de l'éclat de son nourrisson, la blanche Aurore s'avance; la noire déesse a disposé son trône. Toutes deux alliées au Soleil, (l'une comme sa fille, l'autre comme sa mère), toutes deux immortelles, se suivant l'une l'autre, elles parcourent le ciel, l'une à l'autre s'effaçant tour à tour leurs couleurs./ 3. Ce sont deux soeurs qui poursuivent sans fin la même route; elles y apparaissent tour à tour, dirigées par le divin (Soleil). Sans se heurter jamais, sans s'arrêter, couvertes d'une douce rosée, la Nuit et l'Aurore sont unies de pensée et divisées de couleurs./4. Ramenant la parole et la prière, l'Aurore répand ses teintes brillantes; elle ouvre pour nous les portes (du jour). Elle illumine le monde, et nous découvre les richesses (de la nature); elle visite tous les êtres./ 5. Le monde était courbé par le sommeil; tu annonces que le temps est venu de marcher, de jouir de la vie, de songer aux sacrifices, d'augmenter sa fortune. L'obscurité régnait. L'Aurore éclaire au loin l'horizon, et visite tous les êtres./ 6. Richesse, abondance, honneur, sacrifices, voilà des biens vers lesquels tout ce qui respire va marcher à la lumière de tes rayons; l'Aurore va visiter tous les êtres./ 7. Fille du ciel, tu apparais, jeune couvert d'un voile brillant, reine de tous les trésors terrestres; Aurore, brille aujourd'hui fortunée pour nous./ 8. Suivant les pas des Aurores passées, tu es l'ainée des Aurores futures, des Aurores éternelles. Viens ranimer tout ce qui est vivant, Aurore! viens vivifier ce 
Fagundes Varela de poemas sânscritos. Lingua e Literatura, $n^{\circ} 23$. p.151-169, 1997.

qui est mort!/ 9. Aurore, c'est toi qui allumes le feu du sacrifice, toi qui révèles (au monde) la lumière du soleil, toi qui éveilles les hommes pour l'oeuvre sainte. Telle est la noble fonction que tu exerces parmi les dieux./ 10. Depuis combien de temps l'Aurore vient-elle nous visiter? Celle qui arrive aujourd'hui imite les anciennes qui nous ont lui déjà, comme elle sera imitée de celles qui nous luiront encore; elle vient, à la suite des autres, briller pour notre bonheur./ 11 . Ils sont morts, les humains qui voyaient l'éclat de l'antique Aurore; nous aurons leur sort, nous qui voyons celle d'aujourd'hui; ils mourront aussi, ceux qui verront les Aurores futures./ 12. Toi qui repousses nos ennemis, qui favorises les sacrifices, née au moment même du sacrifice; toi qui inspires l'hymne et encourages la prière; toi qui amènes les heureux augures et les rites agréables aux dieux, bonne Aurore, sois-nous aujourd'hui favorable./ 13. Dans les temps passés l'Aurore a brillé avec éclat; de même aujourd'hui elle éclaire richement le monde; de même dans l'avenir elle resplendira. Elle ne connait pas la vieillesse, elle est immortelle; elle s'avance, ornée sans cesse de nouvelles beautés./ 14. De ses clartés elle remplit les régions célestes; déesse lumineuse, elle repousse la noire déesse. Sur son char magnifique traîné par des coursiers rougeâtres, l'Aurore vient, éveillant (la nature)./ 15. Elle apporte les biens nécessaires à la vie de l'homme, elle déploie un étendard brillant; elle nous appelle, pareille aux Aurores qui l'ont toujours précédée, pareille aux Aurores qui la suivront toujours./ 16. Levez-nous; l'esprit vital est venu pour nous. L'obscurité s'éloigne, la lumière s'avance; elle prépare au soleil la voie qu'il doit parcourir. Nous allons reprendre les travaux qui soutiennent la vie./ 17. Le ministre du sacrifice éléve la voix pour célébrer en vers les lumières de l'Aurore. Loin des yeux de celui qui te loue, repousse l'obscurité; Aurore, bénis, en les éclairant de tes rayos, le pére de famille et ses enfants./ 18. Le mortel qui thonore voit briller pour lui des Aurores qui multiplient ses vaches et lui donnent des enfants vigoureux. Puisse celui qui t'offre ces libations accompagnées de la prière (qui résonne) comme un vent (favorable), puisse-t-il obtenir des Aurores fécondes en beaux coursiers!/ 19. Mére des dieux, oeil de la terre, messagère du 
sacrifice, noble Aurore, brille pour nous; approuve nos voeux, et répands sur nous ta lumière. Toi qui fais la joie de tous, rendsnous fameux parmi les nôtres./ 20. Les biens divers qu'apportent les Aurores sont le partage de celui qui le honore et qui les chante. Qu'ils nous protégent également, Mitra, Varouna, Aditi, la Mer, la Terre et le Ciel. 